\title{
New approach to morphometric analysis of Huschke's foramen
}

\author{
H. Çetin ${ }^{1}(0$, S. Akkaşoğlu²(1), S. Çalışkan²(1) \\ ${ }^{1}$ Department of Radiology, Faculty of Medicine, Ankara Yıldırım Beyazıt University, Ankara, Turkey \\ 2Department of Anatomy, Faculty of Medicine, Ankara Yıldırım Beyazıt University, Ankara, Turkey
}

[Received: 31 March 2021; Accepted: 11 May 2021; Early publication date: 25 May 2021]

\begin{abstract}
Background: The aim of the study is to analyse the demographic and anatomical details of the Huschke's foramen (HF) which have not been previously studied and to present a new clinical perspective.

Materials and methods: Multidetector computed tomography (MDCT) images of 495 patients were retrospectively evaluated. Presence of a HF, its' size, relations to side, age and gender were noted for every patient. Size of the foramen was measured in the axial plane, as well as on the reconstructed coronal and sagittal planes.

Results: Of the 495 patients 99 (20\%) had HF. There was no significant difference between females and males according to the presence of the HF and the side of the HF. When the dimension of the left- and the right-sided HFs were compared, there were no significant differences on none of the axes for the patients with unilateral or bilateral HF. There was no significant linear correlation between age and the dimension in the axial axis, the dimension in the sagittal axis and the dimension in the coronal axis

Conclusions: The present work presenting morphologic and statistical variables of HF provides data for further studies which will indicate risk factors of herniation through HF. By the aid of MDCT, which is sensitive method for detection of the HF because of its thin sections, high spatial resolution, and multiplanar capabilities, lesions which were previously diagnosed as dehiscence were found to be defects. (Folia Morphol 2022; 81, 3: 749-755)
\end{abstract}

Key words: Huschke's foramen, multidetector computed tomography, herniation, coronal diameter

\section{INTRODUCTION}

Huschke's foramen (HF) is a developmental defect located on the antero-inferior wall of the external auditory canal (EAC) and communicates this canal to mandibular fossa. HF was first described by German anatomist and embryologist Emil Huschke in 1844 as 'Incisura meatus auditoria externi ossei' (Fig. 1) $[15,16,20]$.
At birth, tympanic plate is a U-shaped, incompletely developed structure. At the first year of life, two ossification points, one anterior and one posterior to $\mathrm{U}$ shaped bone, grow towards each other and fuse. Tympanic plate ossifies and closes around the age of 5 years. Incomplete fusion leads to persistent $\operatorname{HF}[5,6,11]$.

Address for correspondence: Dr. S. Çalışkan, Ankara Yıldırım Beyazıt University, Faculty of Medicine, Department of Anatomy, Ankara, Turkey, tel: +90 5057169390, e-mail: dr.slm.clskn@gmail.com

This article is available in open access under Creative Common Attribution-Non-Commercial-No Derivatives 4.0 International (CC BY-NC-ND 4.0) license, allowing to download articles and share them with others as long as they credit the authors and the publisher, but without permission to change them in any way or use them commercially. 


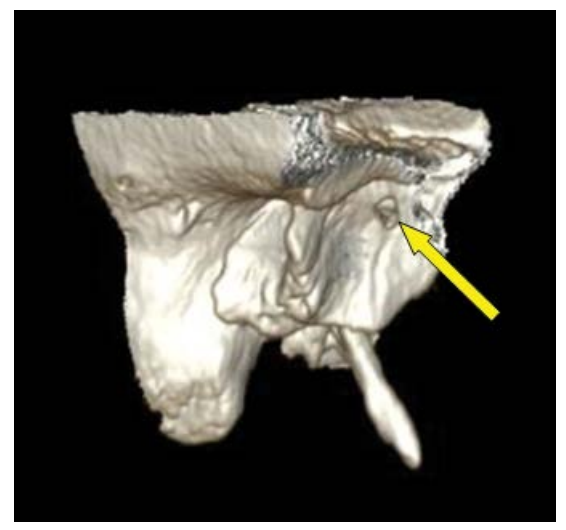

Figure 1. Three-dimensional image of right temporal bone. Defect on the anterior wall of the bony external auditory canal (yellow arrow). Image of mandible is removed.

Incidence of $\mathrm{HF}$ reported in the literature varies in a range from $3 \%$ to $25 \%$. Patients with $\mathrm{HF}$ may be asymptomatic or may suffer from otalgia, otorrhoea, mastication-induced tinnitus, malocclusion and clicking sense during mastication. Moreover temporomandibular joint (TMJ) herniation from HF may lead to conductive hearing loss $[2,4,13,15,17,18,21,23]$.

Otorrhoea in patients with HF may develop due to salivary fistula between parotid gland and EAC $[7,18]$. Clear discharge induced by mastication due to synovial fluid flow through a fistula interconnecting TMJ and EAC is another cause of otorrhoea. HF may present with the drainage of odontogenic abscesses and infectious or tumoural spread [11]. Medical conditions such as persistent otorrhoea, otitis externa, pain, hearing loss, tinnitus, and malocclusion are surgical indications and can be treated by grafts such as fascia, cartilage or miniplates. Conservative therapy options consisting of an anxiolytic, muscle relaxant, and soft diet are also defined in the literature [23, 30].

In the literature, there are radiologic, cadaveric and clinical studies examining HF. In this study, we aimed to define the prevalence and dimensions of the $\mathrm{HF}$ in living individuals based on objective data of multidetector computed tomography (MDCT) images and evaluate the differences related to side and gender. Preoperative detection of HF is an advantage for surgeons to avoid complications. The results of this study will be especially useful for surgeons dealing with otorhinolaryngology.

\section{MATERIALS AND METHODS}

This retrospectively planned radiologic study was carried out in Ankara Yıldırım Beyazıt University Med- ical Faculty. MDCT images of 495 patients obtained for head and neck pathologies from 2019 February to 2020 January were evaluated in the radiology department. A senior radiologist (H.Ç.) analysed the MDCT studies. Patients with history of head trauma, cholesteatoma, mandibular or temporal bone fracture, previous ear surgery and TMJ surgery and those younger than 5 years were not included in this study. The age-, gender- and side-related changes for each measure were statistically analysed.

All CT images were obtained using a 128-MDCT scanner (Revolution EVO, General Electrics Medical Systems USA) with $0.312-\mathrm{mm}$ collimation and a $512 \times 512$ matrix. Transverse scans were acquired in a plane parallel to the orbitomeatal plane in the helical mode with $140 \mathrm{kV}, 280 \mathrm{mAs}$, 1-second rotation time, $0.625-\mathrm{mm}$ section thickness, beam pitch of 0.531 , and field of view of $180 \mathrm{~mm}$. The obtained image data were stored as a DICOM file and were transferred to a workstation, then the CT post processing workstation was used for multiplanar reconstruction, and the main rows of coronal and sagittal image reconstruction was performed. These images were displayed at a window centre of $500 \mathrm{HU}$ and a window width of $3000 \mathrm{HU}$. For every patient, we noted the presence of a foramen and its size. We measured the size of the foramen in the axial plane, as well as on the reconstructed coronal and sagittal planes.

Ethics committee approval was received from Clinical Research Ethics Committee of the Ankara Yıldırım Beyazıt University Medical Faculty (Decision number: 26379996/128).

\section{Statistical analysis}

The distributions of age and the dimensions of the $\mathrm{HF}$ in axial, sagittal and coronal axes were examined by Shapiro-Wilk's test and normality plots. Age was summarised by median (min-max), while both mean \pm standard deviation (mean \pm SD) and median (min-max) were assessed for dimensions. Frequency and percentage (\%) were reported for gender and side.

The males and females were compared with respect to the presence of $\mathrm{HF}$ and its side by $\chi^{2}$ tests. The dimensions of left- and right-sided HFs in axial, sagittal and coronal axes were compared by the independent $t$ test in the patients with unilateral HF and by paired t-test in the patients with bilateral HF. The correlations between the age and dimensions were analysed by Generalised Linear Mixed Model 
Table 1. Distribution of Huschke's foramen (HF) and side based on gender

\begin{tabular}{lcccc}
\hline & Total & Female & Male & P \\
\hline HF & & & & 0.684 \\
Absent & $396(80.0 \%)$ & $175(79.2 \%)$ & $221(80.7 \%)$ & \\
Present & $99(20.0 \%)$ & $46(20.8 \%)$ & $53(19.3 \%)$ & \\
Side & & & & 0.124 \\
Right & $43(35.4 \%)$ & $25(54.3 \%)$ & $18(34.0 \%)$ & \\
Left & $35(43.4 \%)$ & $13(28.3 \%)$ & $22(41.5 \%)$ & \\
Bilateral & $21(21.2 \%)$ & $8(17.4 \%)$ & $13(24.5 \%)$ & \\
\hline
\end{tabular}

Table 2. Dimension of Huschke's foramen in three axes

\begin{tabular}{lcc}
\hline Size $[\mathrm{mm}]$ & Mean \pm SD & Median (min-max) \\
\hline Right $(\mathbf{n}=\mathbf{6 4})$ & & \\
Axial & $3.36 \pm 0.74$ & $3.40(1.6-4.8)$ \\
Sagittal & $3.48 \pm 0.79$ & $3.60(1.9-5.0)$ \\
Coronal & $3.17 \pm 0.73$ & $3.30(1.5-4.3)$ \\
Left ( $\mathbf{n}=\mathbf{5 6 )}$ & \\
Axial & $3.33 \pm 0.96$ & $3.60(1.3-5.2)$ \\
Sagittal & $3.42 \pm 0.95$ & $3.75(1.5-5.3)$ \\
Coronal & $3.16 \pm 0.95$ & $3.45(1.2-5.5)$ \\
\hline SD - standard deviation; min - minimum; max - maximum &
\end{tabular}

Table 3. Dimension comparison of left- and right-sided Huschke's foramen in unilateral and bilateral individuals

\begin{tabular}{|c|c|c|c|c|c|}
\hline & \multicolumn{2}{|c|}{ Left } & \multicolumn{2}{|c|}{ Right } & \multirow[t]{2}{*}{$\mathbf{P}$} \\
\hline & Mean \pm SD & Median (min-max) & Mean \pm SD & Median (min-max) & \\
\hline Unilateral & \multicolumn{2}{|c|}{$N=35$} & \multicolumn{2}{|c|}{$N=43$} & \\
\hline Axial & $3.45 \pm 0.88$ & $3.8(1.3-5.2)$ & $3.43 \pm 0.66$ & $3.4(1.6-4.5)$ & 0.919 \\
\hline Sagittal & $3.55 \pm 0.92$ & $3.8(1.5-5.3)$ & $3.54 \pm 0.72$ & $3.6(1.9-4.8)$ & 0.993 \\
\hline Coronal & $3.23 \pm 0.87$ & $3.4(1.2-5.0)$ & $3.25 \pm 0.70$ & $3.4(1.5-4.3)$ & 0.945 \\
\hline Bilateral & \multicolumn{2}{|c|}{$N=21$} & \multicolumn{2}{|c|}{$N=21$} & \\
\hline Axial & $3.13 \pm 1.06$ & $3.1(1.7-5.1)$ & $3.22 \pm 0.90$ & $3.3(1.8-4.8)$ & 0.813 \\
\hline Sagittal & $3.22 \pm 0.99$ & $3.3(1.9-4.6)$ & $3.36 \pm 0.92$ & $3.6(2.0-5.0)$ & 0.701 \\
\hline Coronal & $3.04 \pm 1.09$ & $3.5(1.5-5.5)$ & $3.01 \pm 0.77$ & $3.2(1.7-4.3)$ & 0.925 \\
\hline
\end{tabular}

SD — standard deviation; min — minimum; max — maximum

(GLMM) with random slope for sides to consider the inter-individual correlation between the dimension measurements. Spearman and Pearson correlation analysis were performed to evaluate the relationship between the age and dimensions of the left- and right-sided HFs, separately. A $p$ value $<0.05$ was considered as statistically significant.

All statistical analyses were performed via IBM SPSS Statistics 22.0 (IBM Corp. Released 2013 IBM SPSS Statistics for Windows, Version 22.0, Armonk, NY, IBM Corp.).

\section{RESULTS}

The median age of 495 individuals was 37 years (min-max: 14-76). Approximately $45 \%(n=221)$ of the individuals were female. Twenty per cent $(n=99)$ had HF. Out of them, 43 (8.7\%) had HF in the right ear, 35 (7.1\%) had HF in the left ear and 21 (4.2\%) had bilateral HF. Of the females, $20.8 \%(n=46)$ and $19.3 \%(n=53)$ of the males were shown to have HF (Table 1). There was no significant difference between females and males according to the presence of HF $(p=0.684)$ and the side of HF $(p=0.124)$.
The mean dimension of the right-sided HFs was $3.36 \pm 0.74 \mathrm{~mm}$ in the axial axis, $3.48 \pm 0.79 \mathrm{~mm}$ in the sagittal axis and $3.17 \pm 0.73 \mathrm{~mm}$ in the coronal axis. The mean and median dimension of the left-sided HFs are given in Table 2.

When the dimension of the left- and the right-sided HFs were compared, there were no significant differences on none of the axes for the patients with unilateral or bilateral HFs (Table 3).

The GLMM analysis showed there was no significant linear correlation between age and the dimension in the axial axis $(p=0.983)$, the dimension in the sagittal axis $(p=0.923)$, and the dimension in the coronal axis ( $p=0.982$ ) of the HF. When the correlation between age and the dimension of the HF was evaluated for left- and right-sided HFs separately, the results were the same $(p>0.05)$.

\section{DISCUSSION}

We encountered many publications in the literature in which HF was analysed by different research techniques based on methodology. Wang et al. [29] found the prevalence of HF was $7.2 \%$ in their osteo- 
logical study on 377 skulls. Bhanu et al. [1] presented $38 \% \mathrm{HF}$ prevalence, but the materials included in the study consisted of skulls and single temporal bones of unknown sexes and age which did not provide accurate data to evaluate demographic statistics. Pękała et al. [19] compared radiologic and osteological studies and concluded that $\mathrm{HF}$ is more prevalent in cadavers $(21.2 \%)$ than in radiologic studies $(8.8 \%)$, but their results are not statistically significant. Osteological studies contribute valuable data to literature but to our opinion exact demographic data and dimensions of an anatomical feature are well defined on radiologic images. Besides, skull collections do not reflect single population and proper dimensions of an anatomical feature may not be claimed clearly due to possible trauma injuries. Age-, gender-, size- and side-related differences of bilateral structures are properly presented in radiologic studies (Table 1).

Tucunduva et al. [27] reported HF prevalence of $12.7 \%$ in their study including 150 patients' cone-bean computed tomography (CBCT) findings. Wang et al. [29] reported prevalence of $0.45 \%$ in osteological study performed on 377 dry skulls. Twelve per cent frequency was reported by Hashimato et al. [8] in their study including 997 dry skulls. In CBCT studies of Deniz et al. (200 cases) [3] and Tozoğlu et al. (207 cases) [26] prevalence of the feature was found $11.5 \%$ and $17.9 \%$, respectively. Our data included MDCT findings of 495 patients and the prevalence detected was $20 \%$ (Table 1). Prevalence of HF in our data is not in consistent with the previously reported prevalence range in the literature. Because of the highly qualified technical details of MDCT device, smaller lesions which were previously misdiagnosed as dehiscence are proven to be defects. To our opinion high prevalence found in the present study is due to advanced technical details of imaging. Besides larger patient number is an additional value of the present study particularly showing the accuracy of descriptive statistics.

Present study provides scientific data to literature by presenting morphometry of $\mathrm{HF}$ and its' relations to side, age and gender. We measured dimensions of $\mathrm{HF}$ in three axes to reveal accurate sizes of this anatomical defect (Figs. 2-5). Of the three axes, coronal diameter, which was found to be the least one, was not measured in the previous publications. Lacout et al. [12] identified the foramina on axial images and confirmed their existence on coronal and sagittal reformatted MDCT images in their study consisting

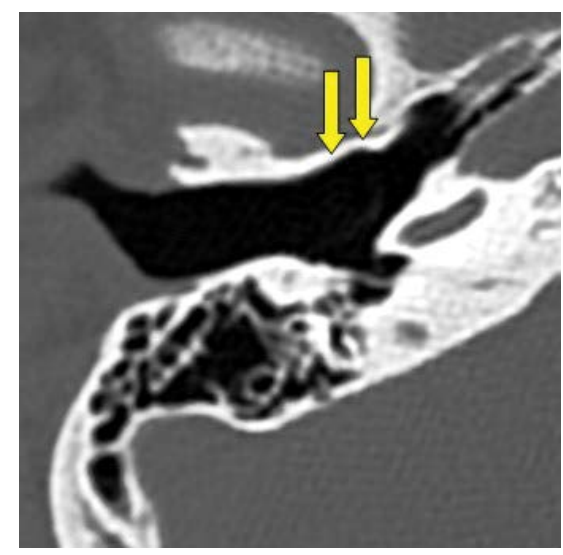

Figure 2. Axial computed tomography image of temporal bone. Normal anteroinferior wall of external auditory canal (yellow arrows).

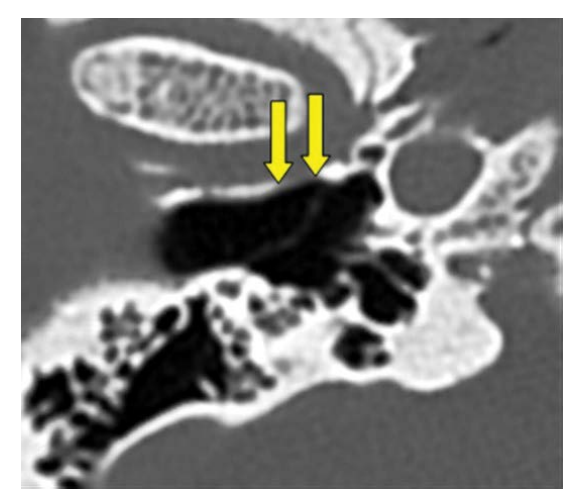

Figure 3. Axial computed tomography image of external auditory canal. Defect on the anterior wall of the bony external auditory canal (yellow arrows).

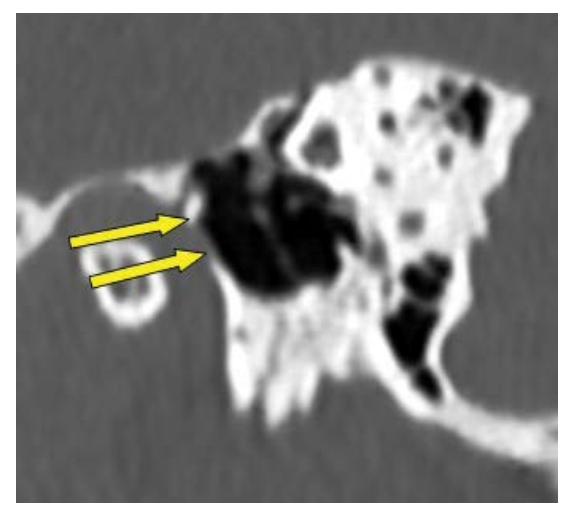

Figure 4. Sagittal computed tomography image of external auditory canal. Defect on the anterior wall of the bony external auditory canal (yellow arrows).

of 102 cases, but they only presented mean size of $4.2 \mathrm{~mm}$ in the axial plane and $3.6 \mathrm{~mm}$ in the sagittal plane. No attribute to coronal measurements was encountered. 


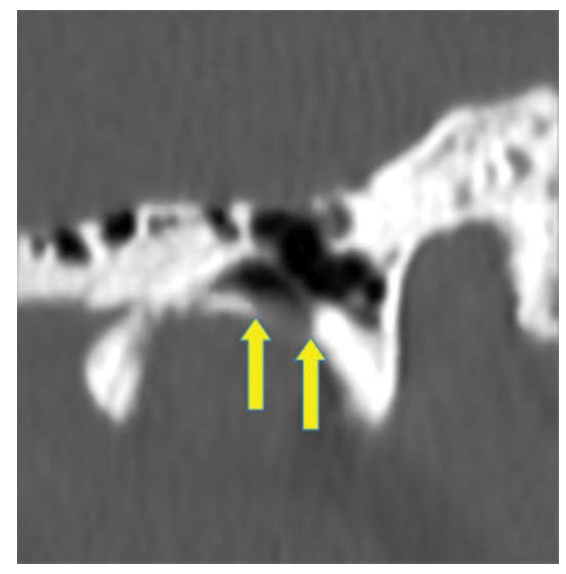

Figure 5. Coronal computed tomography image of external auditory canal. Defect on the anterior wall of the bony external auditory canal (yellow arrows).

Dimensions of an anatomical defect have critical importance to prevent potential complications and should not be measured in one plane. During TMJ arthroscopy, endoscopes with diameter smaller than $3 \mathrm{~mm}$ may cause tympanic membrane perforation, incus dislocation, salivary gland fistula and facial nerve damage by penetrating into the HF [6]. Van der Meer [28] concluded that spread of necrotizing external otitis from EAC to surrounding structures is associated with the increased size of HF. They performed their study on 39 cases with necrotizing external otitis and classified the HF as subtle, mild, moderate, or extensive dehiscence according to maximum width in the axial plane. Diameter of HF was measured only in axial plane in the mentioned study. In our study HF was analysed in three dimensions and coronal diameter was found to be the smallest one (Fig. 5, Tables 2, 3). Misleading point of mentioned study is that the coronal diameter not included in their study is the smallest one. Besides, HF was classified into four groups according to the axial diameter. To our opinion, measurements taken in a single plane are not scientifically appropriate when making a classification based on size.

Size of HF is reported to be an indicator of herniation but we did not come across a study in the literature indicating a cut off value for any diameter of HF which is more likely to allow herniation. Mittal et al. [15] reported that herniation is seen in one fourth of the cases with $\mathrm{HF}$ and is directly related to size of HF. Shapiro and Osborn [23] reported that 30 cases with herniated mandibular condyle into EAC were reported in the international literature. However, least size leading herniation is not presented in both publications. Prospective case series having the patient open and close the mouth while performing MDCT will show the displacement of tissue, which is critical for the diagnosis of the least HF diameter leading herniation. Studies with two stages of radiologic imaging with open and closed mouth will determine cut off value of diameter allowing herniation. Besides it will guide physicians to make the right decision between conservative or surgical treatment options. Although our study has a limitation from this point of view, it can inspire future studies.

Herniated tissue of TMJ through HF may mimic a mass and narrows EAC [28]. Acquired or congenital stenosis of EAC leads to conductive or mixed hearing loss. Differential diagnosis of mass in EAC leading to stenosis consists of exostosis, cholesteatoma or osteoma [14, 22]. Although herniation of TMJ through HF is a rare condition, radiologists may encounter this issue in daily practice [24]. Once this lesion is encountered, accurate differential diagnosis requires radiologist to be well experienced. They should take herniation into consideration when evaluating EAC pathologies. When opening the mouth, forward movement of herniated tissue of TMJ leads to a normal appearance of EAC [23]. It must be kept in mind of surgeons and radiologists to a correct preliminary diagnosis. The present study presenting morphologic and statistical variables of HF provides a data for further studies which will indicate risk factor of herniation through HF.

\section{CONCLUSIONS}

The present study contains complementary data on the missing points of publications in the literature. It was performed by an experienced radiologist on MDCT which is sensitive for detection of the HF because of its thin sections, high spatial resolution, and multiplanar capabilities. All demographic and morphometric details are revealed with the highest number of patients examined to date. To our opinion, the study that would be scientifically valuable to be done in the future is a prospective study that presents cut off value of coronal diameter of HF leading herniation. Present study gives an idea about risk factors of herniation for the suggested future study. 


\section{Acknowledgements}

This evidence based anatomical study was written under the guidelines described in the articles of Henry et al. $[9,10]$ and Tomaszewski et al. [25].

\section{Conflict of interest: None declared}

\section{REFERENCES}

1. Bhanu PS, Sankar KD. Incidence of Foramen of Huschke in South Andhra Population of India. J Clin Diagn Res. 2016; 10(6): AC01-AC03, doi: 10.7860/JCDR/2016/18735.8031, indexed in Pubmed: 27504269.

2. Burlak K, So TY, Maclaurin WA, et al. Foramen tympanicum with symptomatic temporomandibular joint herniation. Radiol Case Rep. 2018; 13(4): 822-824, doi: 10.1016/j. radcr.2018.05.009, indexed in Pubmed: 29988923.

3. Deniz $Y$, Geduk G, Zengin AZ. Examination of foramen tympanicum: an anatomical study using cone-beam computed tomography. Folia Morphol. 2018; 77(2): 335-339, doi: 10.5603/FM.a2017.0078, indexed in Pubmed: 28868610.

4. Ertugrul S. Rare cause of tinnitus: spontaneous temporomandibular joint herniation into the external auditory canal. J Craniofac Surg. 2018; 29(5): e521-e522, doi: $10.1097 /$ SCS.0000000000004579, indexed in Pubmed: 29608483.

5. Ertugrul S, Keskin NK. Relationship between the degree of mastoid pneumatization and the presence of persistent foramen of Huschke. Int J Oral Maxillofac Surg. 2019; 48(8): 1072-1076, doi: 10.1016/j.ijom.2019.01.022, indexed in Pubmed: 30773335.

6. Ertugrul S, Keskin NK. Relationship of age to foramen of Huschke and investigation of the development of spontaneous temporomandibular joint herniation. Int J Oral Maxillofac Surg. 2019; 48(4): 534-539, doi: 10.1016/j. ijom.2018.08.011, indexed in Pubmed: 30205912.

7. Fusconi M, Benfari G, Franco M, et al. Foramen of Huschke: case report and experimental procedure for diagnosis of spontaneous salivary fistula. J Oral Maxillofac Surg. 2009; 67(8): 1747-1751, doi: 10.1016/j.joms.2008.12.065, indexed in Pubmed: 19615593.

8. Hashimoto T, Ojiri H, Kawai Y. The foramen of Huschke: age and gender specific features after childhood. Int J Oral Maxillofac Surg. 2011; 40(7): 743-746, doi: 10.1016/j. ijom.2011.03.017, indexed in Pubmed: 21549561.

9. Henry BM, Tomaszewski KA, Walocha JA. Methods of evidence-based anatomy: a guide to conducting systematic reviews and meta-analysis of anatomical studies. Ann Anat. 2016; 205: 16-21, doi: 10.1016/j. aanat.2015.12.002, indexed in Pubmed: 26844627.

10. Henry BM, Tomaszewski KA, Ramakrishnan PK, et al. Development of the anatomical quality assessment (AQUA) tool for the quality assessment of anatomical studies included in meta-analyses and systematic reviews. Clin Anat. 2017; 30(1): 6-13, doi: 10.1002/ca.22799, indexed in Pubmed: 27718281.

11. Jaju PP. Cone beam CT detection of foramen tympanicum or foramen of Huschke. Dentomaxillofac Radiol. 2012; 41(7): 619, doi: 10.1259/dmfr/50909630, indexed in Pubmed: 22933530.
12. Lacout A, Marsot-Dupuch K, Smoker WRK, et al. Foramen tympanicum, or foramen of Huschke: pathologic cases and anatomic CT study. Am J Neuroradiol. 2005; 26(6): 1317-1323, indexed in Pubmed: 15956489.

13. Lim KH, Jung JY, Rhee J, et al. Temporomandibular joint herniation through the foramen of Huschke with clicking tinnitus. Eur Ann Otorhinolaryngol Head Neck Dis. 2019; 136(6): 497-499, doi: 10.1016/j.anorl.2018.05.014, indexed in Pubmed: 31010735.

14. Magliulo G. Acquired atresia of the external auditory canal: recurrence and long-term results. Ann Otol Rhinol Laryngol. 2009; 118(5): 345-349, doi: 10.1177/000348940911800505, indexed in Pubmed: 19548383.

15. Mittal S, Singal S, Mittal A, et al. Identification of foramen of Huschke with reversible herniation of temporomandibular joint soft tissue into the external auditory canal on multidetector computed tomography. Proc (Bayl Univ Med Cent). 2017; 30(1): 92-93, doi: 10.1080/08998280.2017.11929544, indexed in Pubmed: 28127148

16. Moreno R, Chilvarquer I, Hayek J, et al. Anatomic and radiograph study of the persistence of Foramen of Huschke. Braz J Otorhinolaryngol. 2005; 71(5): 676-679, doi: 10.1016/s1808-8694(15)31273-8.

17. Nakasato T, Nakayama T, Kikuchi K, et al. Spontaneous temporomandibular joint herniation into the external auditory canal through a persistent foramen tympanicum (Huschke): radiographic features. J Comput Assist Tomogr. 2013; 37(1): 111-113, doi: 10.1097/ RCT.0b013e318272ef04, indexed in Pubmed: 23321842.

18. Park YHo, Kim HJ, Park MH. Temporomandibular joint herniation into the external auditory canal. Laryngoscope. 2010; 120(11): 2284-2288, doi: 10.1002/lary.21115, indexed in Pubmed: 20939076.

19. Pękala JR, Pękala PA, Satapathy B, et al. Incidence of Foramen Tympanicum (of Huschke): Comparing Cadaveric and Radiologic Studies. J Craniofac Surg. 2018; 29(8): 2348-2352, doi: 10.1097/SCS.0000000000004784, indexed in Pubmed: 30277949.

20. Pirsig W, Mudry A. Huschke's anterior external auditory canal foramen: art before medicine? Otol Neurotol. 2015; 36(3): 555-560, doi: 10.1097/MAO.0000000000000418, indexed in Pubmed: 24786542.

21. Prowse SJ, Kelly G, Agada F. Temporomandibular joint herniation and the foramen of Huschke: an unusual external auditory canal mass. J Laryngol Otol. 2011; 125(12): 1279-1281, doi: 10.1017/S0022215111002295, indexed in Pubmed: 21910955.

22. Sanna M, Russo A, Khrais T, et al. Canalplasty for severe external auditory meatus exostoses. J Laryngol Otol. 2004; 118(8): 607-611, doi: 10.1258/0022215041917808, indexed in Pubmed: 15453935.

23. Shapiro MC, Osborn T. Temporoparietal fascia flap and total temporomandibular joint replacement for the management of patent foramen of Huschke. Int J Oral Maxillofac Surg. 2016; 45(8): 1023-1026, doi: 10.1016/j. ijom.2016.03.006, indexed in Pubmed: 27066740.

24. Shin JE, Jeong $\mathrm{KH}$, Ahn SH, et al. Temporomandibular joint herniation into the external auditory canal: two 
cases involving a persistent foramen tympanicum. J Craniofac Surg. 2015; 26(4): e331-e333, doi: 10.1097/ SCS.0000000000001630, indexed in Pubmed: 26080253.

25. Tomaszewski KA, Henry BM, Kumar Ramakrishnan P, et al. Development of the anatomical quality assurance (AQUA) checklist: guidelines for reporting original anatomical studies. Clin Anat. 2017; 30(1): 14-20, doi: 10.1002/ ca.22800, indexed in Pubmed: 27801507.

26. Tozoglu U, Caglayan F, Harorli A. Foramen tympanicum or foramen of Huschke: anatomical cone beam CT study. Dentomaxillofac Radiol. 2012; 41(4): 294-297, doi: $10.1259 / \mathrm{dmfr} / 62359484$, indexed in Pubmed: 22517996.

27. Tucunduva RM, Lopes IA, Shinohara AL, et al. Usefulness of cone-bean computed tomography exams to detect foramen of huschke in diverse age group. J Craniofac Surg. 2019; 30(2): e138-e141, doi: 10.1097/SCS.0000000000005069, indexed in Pubmed: 30570591.

28. van der Meer $\mathrm{WL}$, van Tilburg M, Mitea $\mathrm{C}$, et al. A persistent foramen of huschke: a small road to misery in necrotizing external otitis. Am J Neuroradiol. 2019; 40(9): 1552-1556, doi: 10.3174/ajnr.A6161, indexed in Pubmed: 31395661.

29. Wang RG, Bingham $B$, Hawke $M$, et al. Persistence of the foramen of Huschke in the adult: an osteological study. J Otolaryngol. 1991; 20(4): 251-253, indexed in Pubmed: 1920577.

30. Yoo MH, Park JW, Lee HS, et al. Repair of the foramen of Huschke using an extended endaural approach. Laryngoscope. 2016; 126(9): 2137-2139, doi: 10.1002/lary.25718, indexed in Pubmed: 26466967. 